\title{
THE INFLUENCE OF SMALL CLEARANCES IN THE SPHERICAL JOINTS OF THE SYSTEMS ON THEIR DYNAMIC RESPONSE
}

\author{
Doina BOAZU \\ Department of Mechanical Engineering, “Dunărea de Jos” University of Galaţi, \\ doina.boazu@ugal.ro
}

\begin{abstract}
The paper highlights the influence of small clearances in the spherical joints on their natural frequencies and modes of vibration. Joints with bearings made of materials that involve low friction in the coupling (Teflon and HDPE polyethylene) were considered. Two cases of coupling by means of the spherical joints were considered, namely: the coupling angle of the bars in the spherical joint being of $0^{0}$ and of $90^{\circ}$, respectively.

The size of the clearance influences the first natural frequency of the system in the sense of decreasing it, but also in the modification of the vibration modes of the system when even a small clearance appears in the joint.
\end{abstract}

KEYWORDS: clearances in spherical joints, dynamic response, FEM analysis

\section{INTRODUCTION}

Spherical joints are important for their widespread use in mechanical structures.

The modification of the clearance affects the dynamic response of the entire mechanical structure through the nonlinearity introduced by the contact. There are concerns for making models of contact in the spherical joint in which there are large clearance [2], [4]. These models target traditional contact schemes and schemes based on the Winkler model and by modeling clearance using FEM [7].

A computational methodology for analysis of spatial flexible multibody systems, considering the effects of the clearances and lubrication in the system spherical joints, is presented in the paper [5].

The results presented in [6] show that the joint clearance makes the mechanism performance worse; the flexibility of pivot has a clear suspension effect to minimize the negative outputs of joint clearance on mechanisms.
In this paper, the size of the clearance (GAP) is introduced practically by modifying the contact rigidity which also depends on the compression behavior of the joint materials. In the Ansys Workbench program within the contact conditions, there is the possibility of generating a GAP between the surfaces in contact (a negative offset) in Fig. 1.1a (a GAP of 6e-006 m) [1]. The contact surfaces (contact surface-red color and target surface-blue color) for the two types of angles of the bars in the spherical couple are given in Fig. 1.b and Fig. 1.c.

\begin{tabular}{l} 
Details of "Frictionless - Solid To Solid" \\
\begin{tabular}{|l|l|}
\hline Time Step Controls & None \\
\hline Geometric Modification & \\
\hline Interface Treatment & Add Offset, No Ramping \\
\hline$\square$ Offset & $-6 . e-006 \mathrm{~m}$ \\
\hline Contact Geometry Correction & None \\
\hline Target Geometry Correction & Smoothing \\
\hline Target Orientation & Sphere Center Point \\
\hline Target Center Point & Global Coordinate System \\
\hline
\end{tabular} \\
\hline
\end{tabular}

Fig. 1.a. Introducing the GAP in the spherical joint in Ansys Workbench 


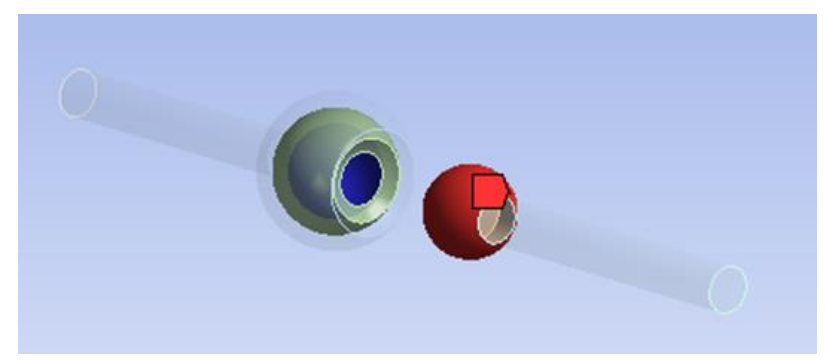

Fig. 1.b. Contact surfaces for the spherical joint angle of $0^{\circ}$

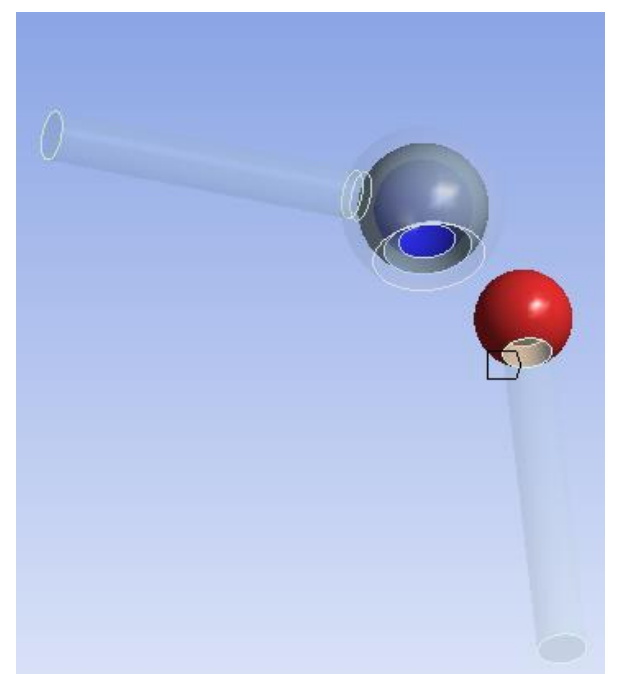

Fig. 1.c. Contact surfaces for the spherical joint angle of $90^{\circ}$

Table 1. Material properties for Modal analysis

\begin{tabular}{|l|l|l|l|}
\hline & Mass density $\left[\mathrm{kg} / \mathrm{m}^{\wedge} 3\right]$ & $\begin{array}{l}\text { Young modulus in } \\
\text { compression }[\mathrm{Pa}]\end{array}$ & Poisson ratio \\
\hline Structural Steel & 7850 & $2.1 \mathrm{e}^{\wedge} 11$ & 0.3 \\
\hline Teflon & 2160 & $482 \mathrm{e}^{\wedge} 6$ & 0.42 \\
\hline Polyethylene HDPE & 960 & $110 \mathrm{e}^{\wedge} 6$ & 0.42 \\
\hline
\end{tabular}

The spherical joint model was created in the Ansys Workbench program. The contact in the joint is made between the spherical head of a steel rod (Structural Steel) and a piece of Teflon / HDPE polyethylene as a bearing, fixed on the spherical wall of the head of the other steel rod. The one that will have the radial dimensions modified to create the radial play will be the piece made of Teflon / HDPE polyethylene; because the friction between steel and Teflon / HDPE polyethylene is small and the contact was considered frictionless.

The length of the bars $l=120 \mathrm{~mm}$, and the outer diameter of the spherical cap is $d=50 \mathrm{~mm}$.

The matrix equation for the free vibration of the system is:

$$
[M]\{\ddot{\Delta}\}+[K]\{\Delta\}=\{0\}
$$

in which $[\mathrm{M}]$ is the mass matrix, $[\mathrm{K}]$ is the stiffness matrix, $\{\ddot{\Delta}\}$ is the acceleration's vector, and $\{\Delta\}$ is the displacement's vector.

Eigenvalues and eigenvectors of the equation were obtained from the Ansys Workbench program, using Subspace Iteration [1].

Although the introduction of contact elements involves a nonlinear approach, and the calculation of frequencies and eigenmodes is linear, the exclusion of friction allows the introduction of a GAP in the spherical joint by changing the contact stiffness that remains fixed.
The type of element used in discretization is SOLID187 (number of nodes 7485, number of elements 1981).

\section{SIMPLIFIED MODEL OF A SPHERICAL JOINT WITH AXES AT $0^{0}$}

The boundary conditions for the joint in which the angle of the bars in the coupling is $0^{0}$ is represented in Fig. 2.a, and the components of the joint are represented in Fig. 2.b. The ends of the bars are fixed to highlight the influence of the change of contact rigidity on the dynamic response of the assembly.

The first five natural modes of vibration of the spherical joint with the system bars at $0^{0}$ are shown in Fig. 3 - Fig. 7 (Teflon as a bearing material and GAP $=0$ ).

The first five natural modes of vibration of the spherical joint with the system bars at $0^{0}$ are shown in Fig. 8 - Fig. 12 (Teflon as a bearing material and $\mathrm{GAP}=1 \mathrm{~mm})$

The influence of the size of the radial GAP in the spherical joint on the first 5 natural modes of vibration can be followed in Table 2 and Fig. 13. In Fig. 13 also appears the curve of linear approximation of the influence of the GAP in mm on the first natural frequency of the system in $\mathrm{Hz}$. 


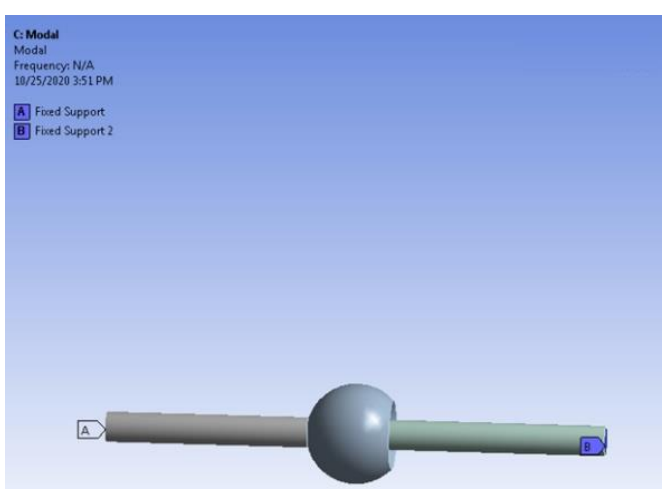

Fig. 2.a. The boundary conditions for the coupling angle in the spherical joint is $0^{\circ}$

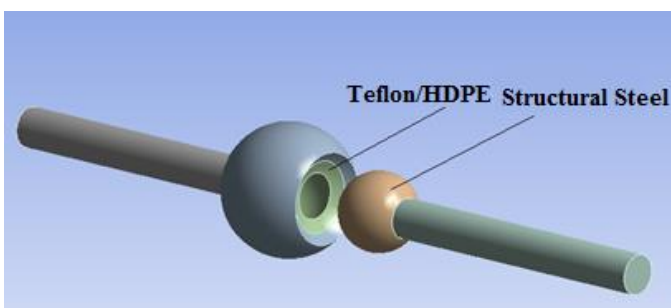

Fig. 2.b. Joint components (Teflon piece (sleeve) and spherical steel head)

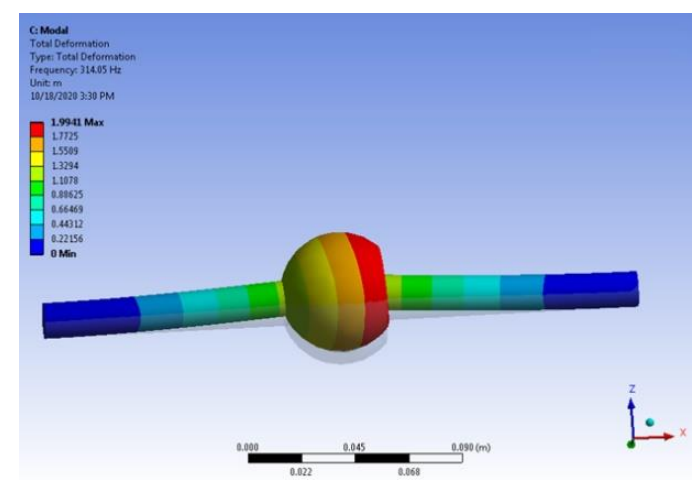

Fig. 3. The vibration mode $1\left(G A P=0\right.$, angle of $\left.0^{\circ}\right)$

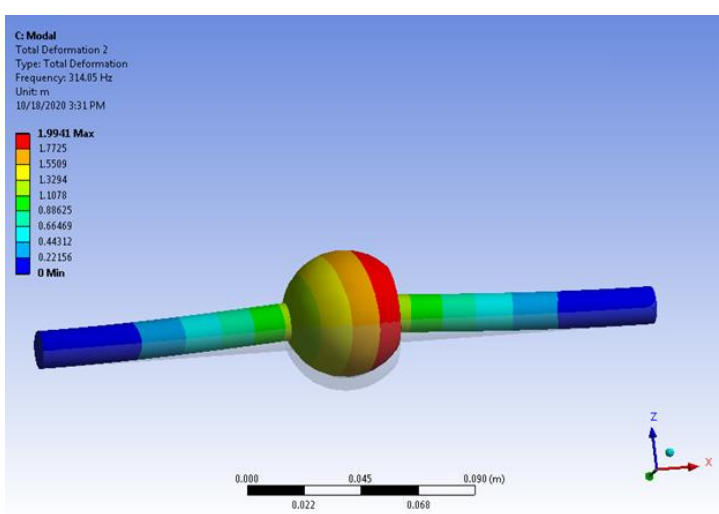

Fig. 4. The vibration mode $2\left(G A P=0\right.$, angle of $\left.0^{\circ}\right)$

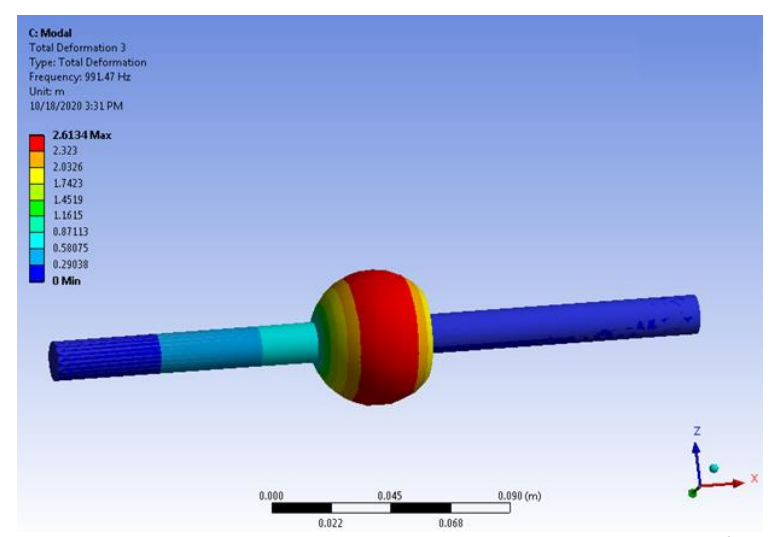

Fig. 5. The vibration mode $3\left(G A P=0\right.$, angle of $\left.O^{\circ}\right)$

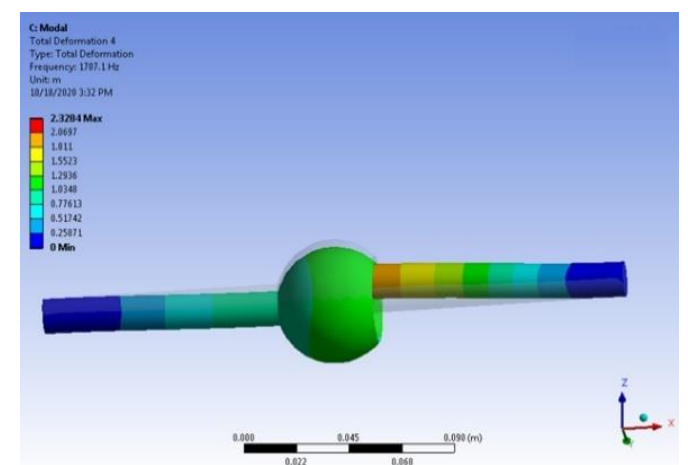

Fig. 6. The vibration mode $4\left(G A P=0\right.$, angle of $\left.O^{\circ}\right)$

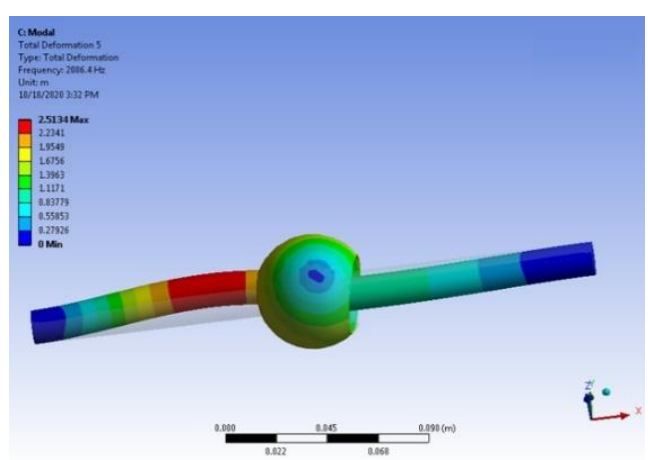

Fig. 7. The vibration mode $5\left(G A P=0\right.$, angle of $\left.O^{\circ}\right)$

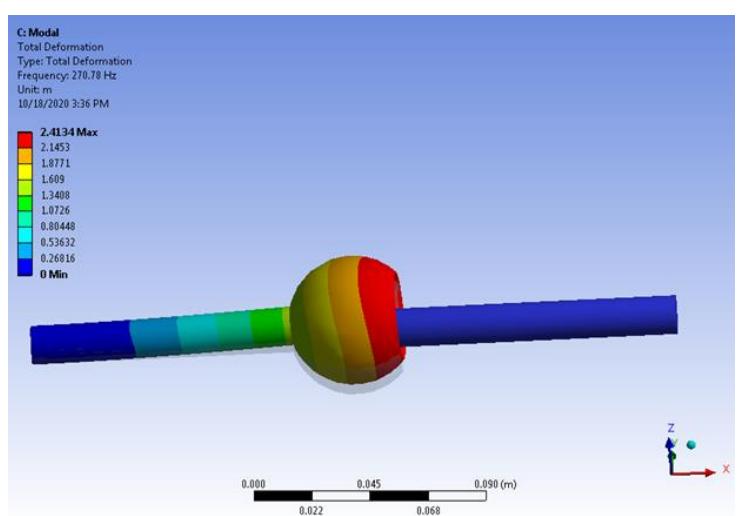

Fig. 8. The vibration mode 1 $\left(G A P=1 e-3 m\right.$, angle of $\left.O^{\circ}\right)$ 


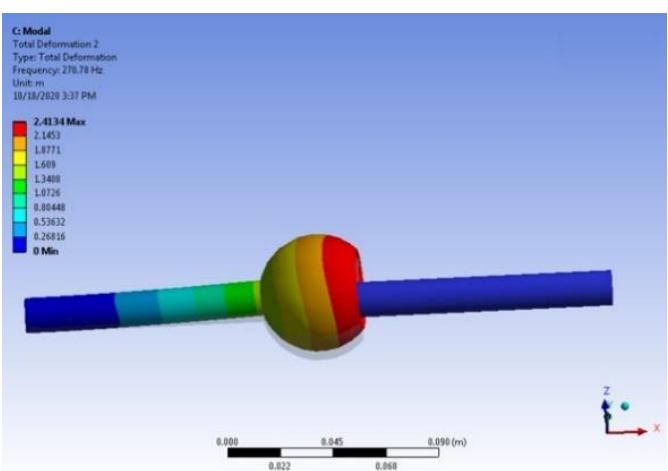

Fig. 9. The vibration mode 2

$\left(G A P=1 e-3 m\right.$, angle of $\left.0^{\circ}\right)$

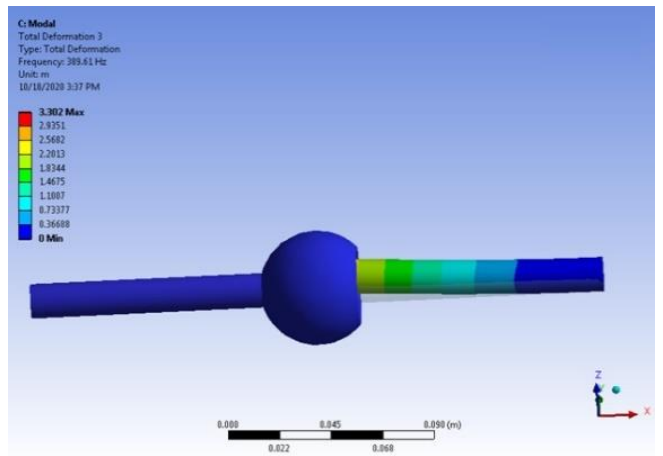

Fig. 10. The vibration mode 3 $\left(G A P=1 e-3 m\right.$, angle of $\left.O^{\circ}\right)$

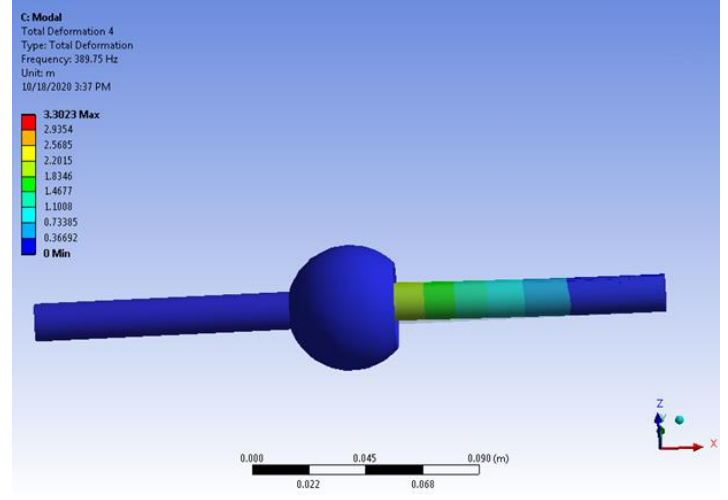

Fig. 11. The vibration mode 4 $\left(G A P=1 e-3 m\right.$, angle of $\left.O^{\circ}\right)$

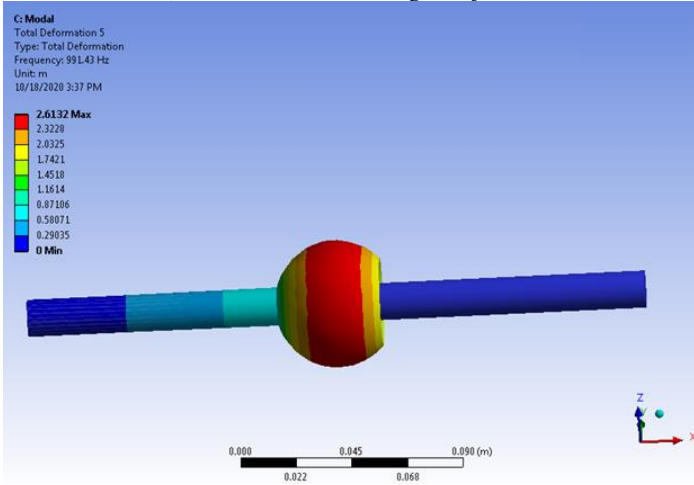

Fig. 12. The vibration mode 5 $\left(G A P=1 e-3 m\right.$, angle of $\left.O^{\circ}\right)$

Table 2. The first five natural frequencies in the spherical joint with bars coupled at an angle of $0^{0}$ (Teflon as a bearing material)

\begin{tabular}{|c|c|c|c|}
\hline \multirow{2}{*}{$\begin{array}{c}\text { Mode } \\
\text { number }\end{array}$} & \multicolumn{3}{|c|}{ Natural frequencies in $[\mathrm{Hz}]$} \\
\hline 1 & GAP=0 & GAP=10e-6 m & GAP=1e-3 m \\
\hline 2 & 314.05 & 312.69 & 270.78 \\
\hline 3 & 314.45 & 314.28 & 270.91 \\
\hline 4 & 991.47 & 991.43 & 389.61 \\
\hline 5 & 1707.1 & 1060.4 & 389.75 \\
\hline
\end{tabular}

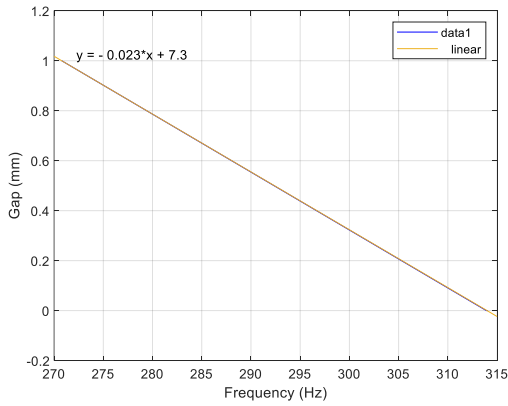

Fig. 13. Joint GAP vs the first natural frequency for the coupling angle in the spherical joint of $0^{\circ}$ (Teflon as a bearing material) $y=p 1 * x+p 2$; Coefficients: $p 1=-0.023148 ; p 2=7.268 ;$ Norm of residuals $=$ 0.0022869

\section{SIMPLIFIED MODEL OF A SPHERICAL JOINT WITH AXES AT 900}

The boundary conditions for the joint in which the angle of the bars in the coupling is $90^{\circ}$ is represented in Fig. 14a, and the components of the joint are represented in Fig. 14b. The ends of the bars are fixed to follow only the influence of the change of contact rigidity on the dynamic response of the spherical joint.

The first five natural modes of vibration of the spherical joint with the system bars at $90^{\circ}$ are shown in Figs. 15, Fig. 19 (Teflon as bearing material and GAP $=0)$.

The first five natural modes of vibration of the spherical joint with the system bars at $90^{\circ}$ are shown in Figs. 20, Fig. 24 (Teflon as bearing material and $\mathrm{GAP}=7.5 \mathrm{e}-6 \mathrm{~m})$ ). 
The influence of the size of the radial GAP in the spherical joint on the first 5 natural modes of vibration can be followed in Table 1.3 and Fig. 25 . Also, in Fig. 25, the curve of linear approximation of the influence of the GAP in $\mathrm{mm}$ on the first natural frequency of the system in $\mathrm{Hz}$ appears.

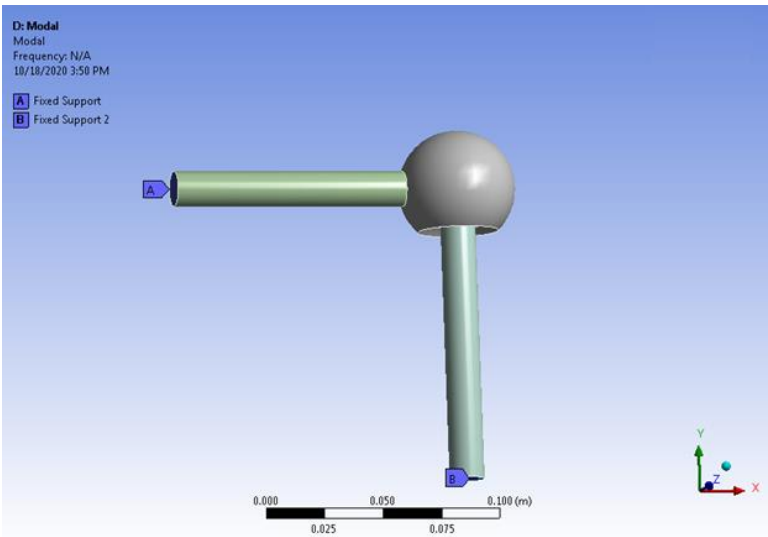

Fig. 14.a. Boundary conditions for the coupling angle of $90^{\circ}$

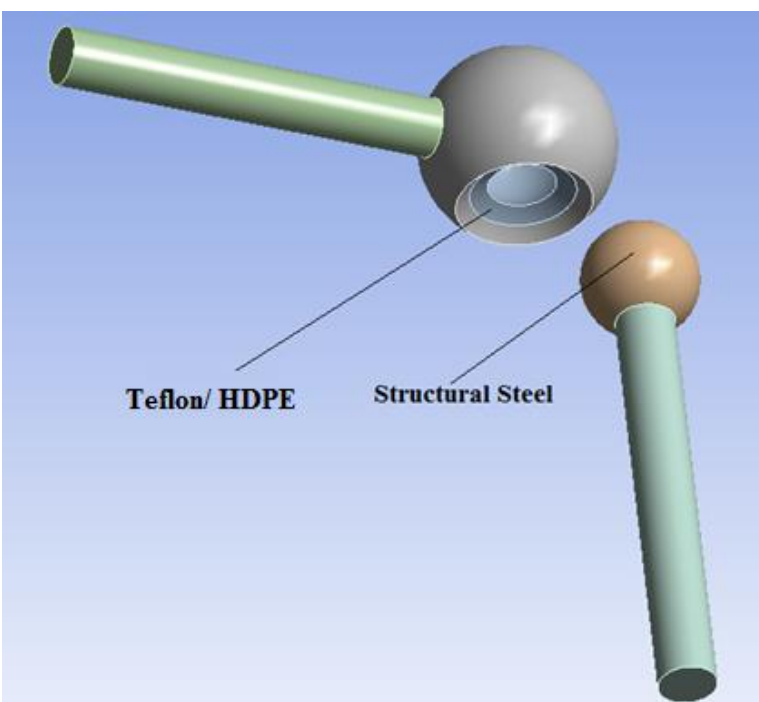

Fig. 14.b. Joint components (Teflon piece (sleeve) and spherical steel head)

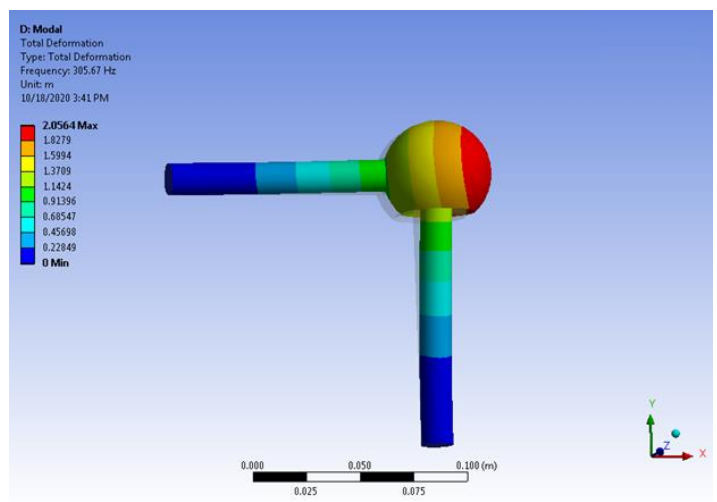

Fig. 15. The vibration mode $1\left(G A P=0\right.$, angle of $\left.90^{\circ}\right)$

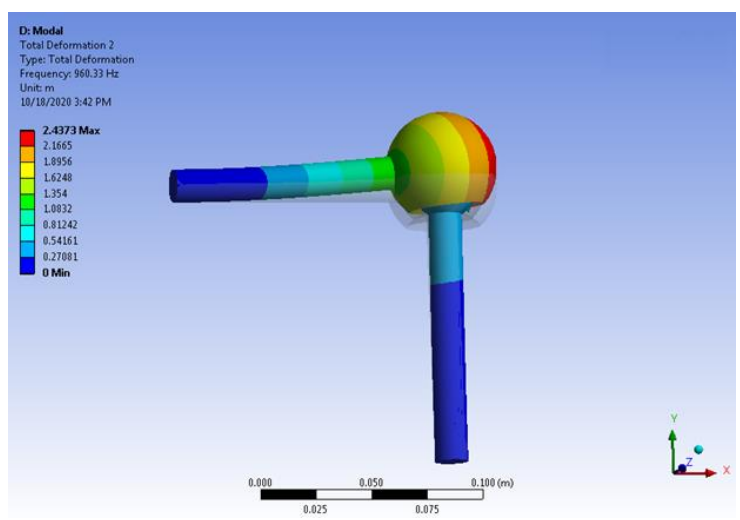

Fig. 16. The vibration mode $2\left(G A P=0\right.$, angle of $\left.90^{\circ}\right)$

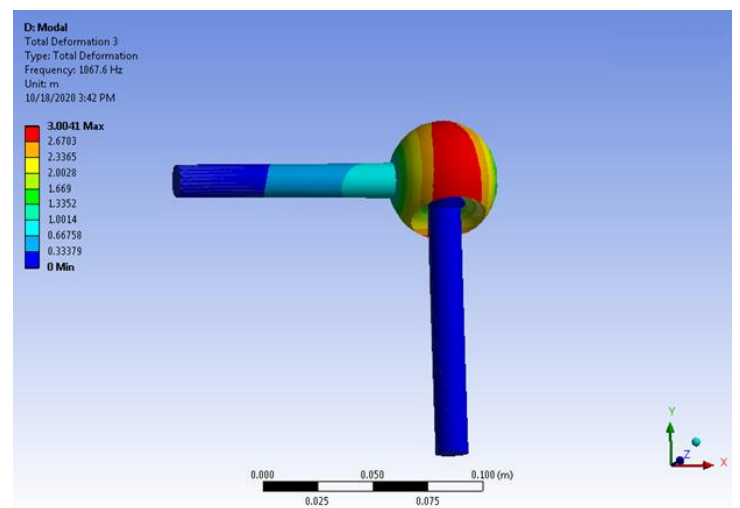

Fig. 17. The vibration mode $3\left(G A P=0\right.$, angle of $\left.90^{\circ}\right)$

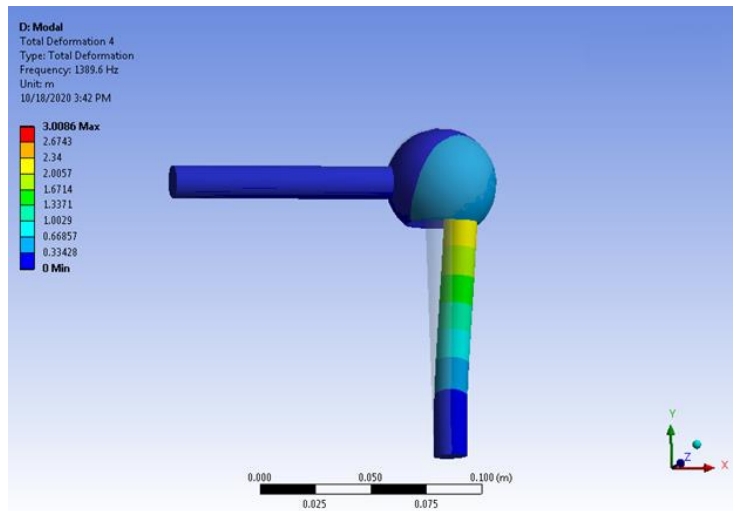

Fig. 18. The vibration mode $4\left(G A P=0\right.$, angle of $\left.90^{\circ}\right)$

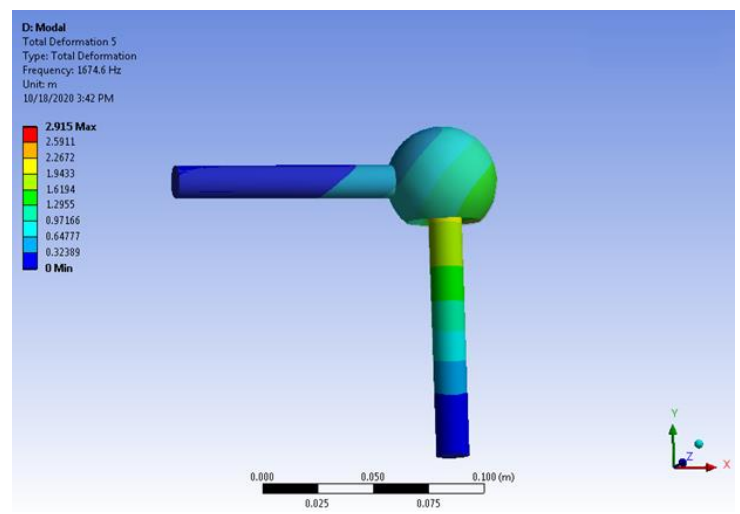

Fig. 19. The vibration mode $5\left(G A P=0\right.$, angle of $\left.90^{\circ}\right)$ 


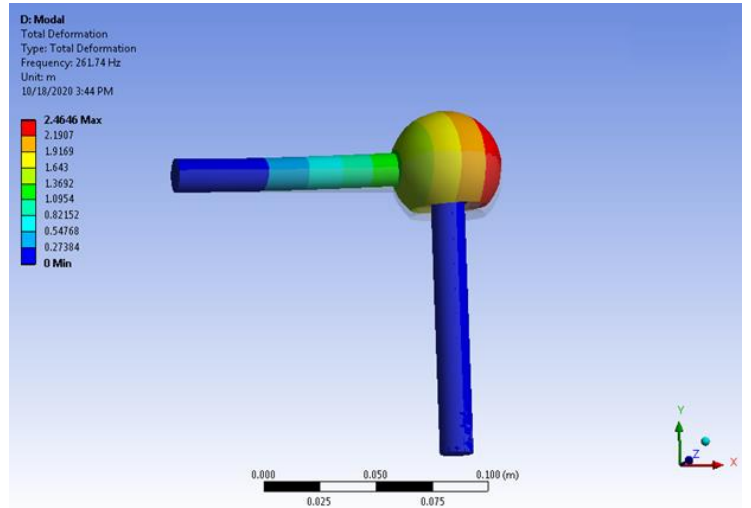

Fig. 20. The vibration mode 1 $\left(G A P=7.5 e-6 m\right.$, angle of $\left.90^{\circ}\right)$

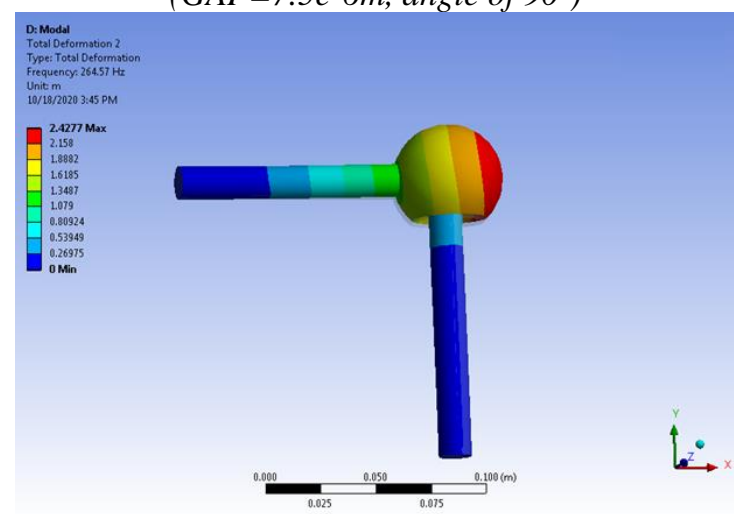

Fig. 21. The vibration mode 2 $\left(G A P=7.5 e-6 m\right.$, angle of $\left.90^{\circ}\right)$

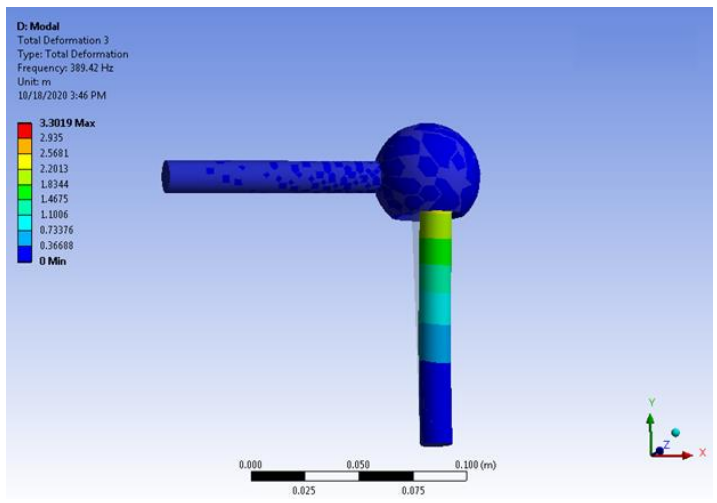

Fig. 22. The vibration mode 4 $\left(G A P=7.5 e-6 m\right.$, angle of $\left.90^{\circ}\right)$

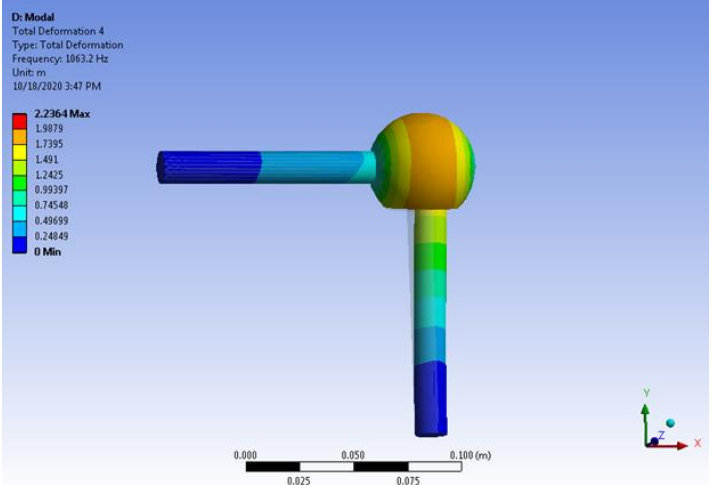

Fig. 23. The vibration mode 4 $\left(G A P=7.5 e-6 m\right.$, angle of $\left.90^{\circ}\right)$

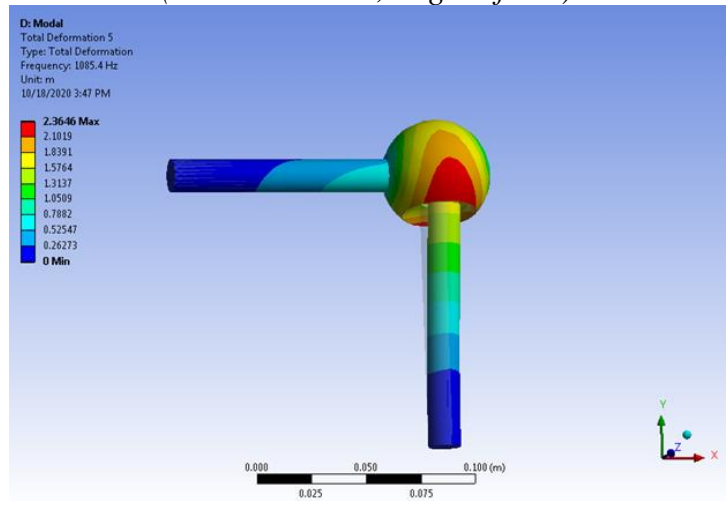

Fig. 24. The vibration mode 5 $\left(G A P=7.5 e-6 m\right.$, angle of $\left.90^{\circ}\right)$

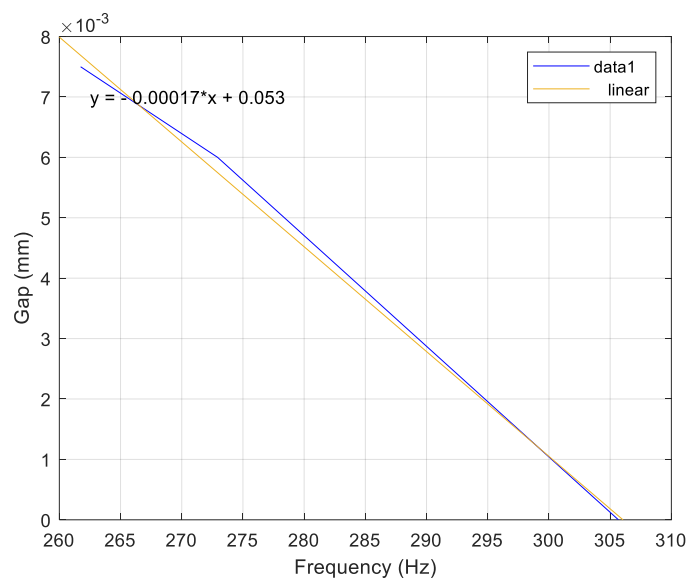

Fig. 25. Joint GAP vs the first natural frequency for the coupling angle in the spherical joint of $90^{\circ}$ (Teflon as bearing material) $y=p 1 * x+p 2$; Coefficients: $p 1$ $=-0.00017353 \mathrm{p} 2=0.053108$ Norm of residuals $=$ 0.00032223

Table 3. The first five natural frequencies in the spherical joint with bars coupled at an angle of $90^{\circ}$ (Teflon as a bearing material)

\begin{tabular}{|c|c|c|c|}
\hline \multirow{2}{*}{$\begin{array}{c}\text { Mode } \\
\text { number }\end{array}$} & \multicolumn{3}{|c|}{ Natural frequencies in [Hz] } \\
\cline { 2 - 4 } & GAP=0 & GAP=6 e-6m & GAP=7.5e-6m \\
\hline 1 & 305.69 & 272.93 & 261.74 \\
\hline 2 & 960.33 & 384.12 & 264.55 \\
\hline 3 & 1067.6 & 567.49 & 389.42 \\
\hline 4 & 1389.6 & 1072.9 & 1063.2 \\
\hline 5 & 1664.5 & 1275.3 & 1085.4 \\
\hline
\end{tabular}


Table 4. The first five natural frequencies in the spherical joint with bars coupled at an angle of $0^{\circ}$ (HDPE as a bearing material)

\begin{tabular}{|c|c|c|c|}
\hline \multirow{2}{*}{$\begin{array}{c}\text { Mode } \\
\text { number }\end{array}$} & \multicolumn{3}{|c|}{ Natural frequencies in $[\mathrm{Hz}]$} \\
\hline 1 & GAP=0 & GAP=10 e-6m & GAP=1e-3 m \\
\hline 2 & 320.71 & 316.35 & 281.87 \\
\hline 3 & 321.92 & 321.46 & 389.61 \\
\hline 4 & 905.94 & 610.08 & 389.75 \\
\hline 5 & 1017.9 & 1017.9 & 1017.9 \\
\hline
\end{tabular}

Table 5. The first five natural frequencies in the spherical joint with bars coupled at an angle of $90^{\circ}(H D P E$ as a bearing material)

\begin{tabular}{|c|c|c|c|}
\hline \multirow{2}{*}{$\begin{array}{c}\text { Mode } \\
\text { number }\end{array}$} & \multicolumn{3}{|c|}{ Natural frequencies in $[\mathrm{Hz}]$} \\
\hline 1 & GAP=0 & GAP=10 e-6m & GAP=1e-3 m \\
\hline 2 & 311.6 & 307.26 & 271.17 \\
\hline 3 & 544.6 & 456.92 & 272.37 \\
\hline 4 & 764.28 & 592.58 & 389.41 \\
\hline 5 & 878.52 & 751.47 & 389.44 \\
\hline
\end{tabular}

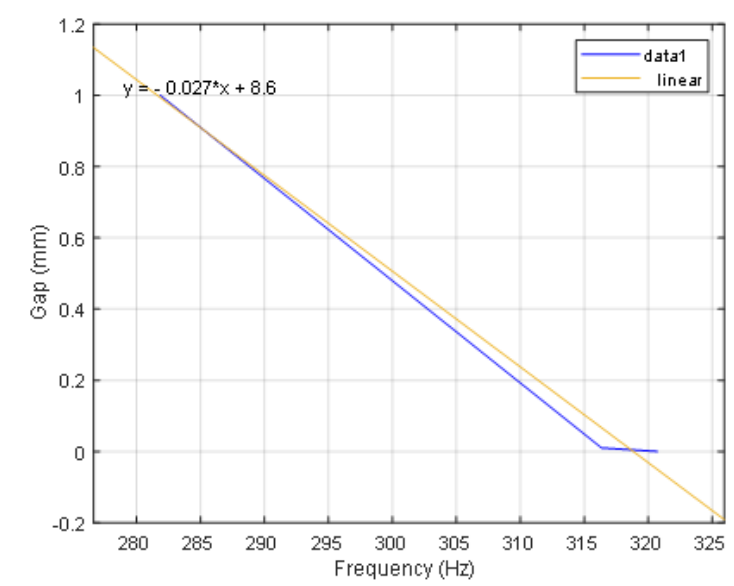

Fig. 26. Joint GAP vs the first natural frequency for the coupling angle in the spherical joint of $O^{\circ}$ (HDPE as bearing material) $y=p 1 * x+p 2$ Coefficients: $p 1=$ $-0.02688 ; p 2=8.5704 ;$ Norm of residuals $=$ 0.076202

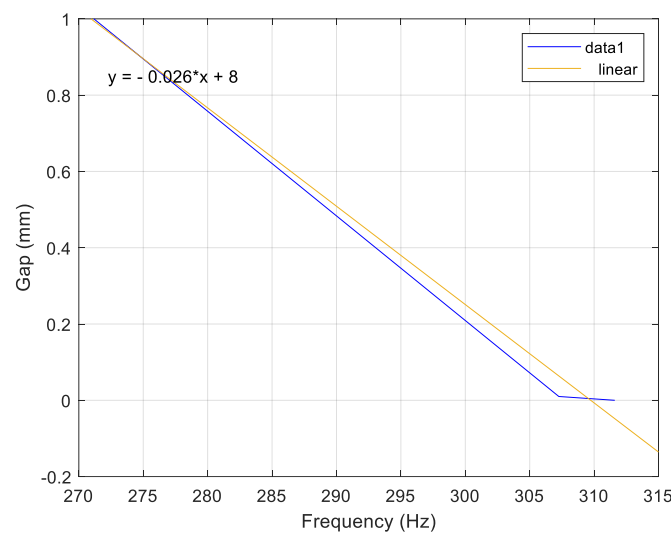

Fig. 27. Joint GAP vs the first natural frequency for the coupling angle in the spherical joint of $90^{\circ}$ (HDPE as bearing material) $y=p 1 * x+p 2$ Coefficients: $p 1=-0.02578 ;$ p2 = 7.9849; Norm of residuals $=0.07239$

\section{CONCLUSIONS}

The influence of the size of the radial clearance in the spherical joint with the bars at an angle of $0^{0}$, in which the bushing is made of HDPE polyethylene on the first 5 natural frequencies can be followed in Table 14. In Fig. 26 is presented the curve of linear approximation of the influence of the play in $\mathrm{mm}$ on the first natural frequency of the system in $\mathrm{Hz}$.

The influence of the size of the radial clearance (the GAP) in the spherical joint with bars at an angle of $90^{\circ}$, in which the bushing is made of HDPE polyethylene on the first 5 natural vibration frequencies can be followed in Table 15. Fig. 27 presents the curve of linear approximation of the influence of the play in $\mathrm{mm}$ on the first natural frequency of the system in $\mathrm{Hz}$.

The mechanical characteristics of the spherical joint bearing materials (Table 1) influence to a small extent the size of the fundamental frequency (Tables 2 and 3 for the Teflon and Tables 4 and 5 for the UHPE).

From the analysis of the natural modes of vibration of the systems with and without GAP, it results that the appearance of the GAP in the spherical joint decouples the movements of the bodies within the first natural mode of vibration. Also, the natural modes 2-5 are different for the cases without GAP and with a small GAP. The size of the GAP in the spherical joint "controls" the first natural frequency of the structure (the rigidity of the structure is reduced by changing the contact rigidity) [3].

As the size of the GAP increases, the fundamental frequency decreases. If the GAP has a considerable amount, some rigid modes appear (having natural frequency $=0$ ), which in real situations will generate a shock operation in the system.

The GAP in the spherical joint that appears from the wear of the bearing piece has a negative influence on the dynamic operation regime of the assembly. 
Even a small GAP in the spherical joint changes its fundamental frequency and its associated mode.

The length of the bars has an influence on the flexibility of the structure and modifies the response of the system with GAP, i.e. it makes it sensitive to large GAP in the spherical joint.

\section{REFERENCES}

[1]. ****, Ansys Workbench version 19.2 documentation;

[2]. Cai-Shan Liu, Ke Zhang, Lei Yang, Normal ForceDisplacement Relationship of Spherical Joints with Clearances, J. Comput. Nonlinear Dynam. Apr 2006, 1(2): 160-167 (8 pages), https://doi.org/10.1115/1.2162872

[3]. Gingarasu M., Research and contributions on diagnosing the technical condition of vehicles (in Romanian Cercetări și contribuții privind diagnosticarea stării tehnice a autovehiculelor), doctoral Thesis, University "Dunarea de Jos" of Galati, Feb. 2021.
[4]. Qiang Tian, Yunqing Zhang, Liping Chen, Paulo Flores, Dynamics of spatial flexible multibody systems with clearance and lubricated spherical joints, Computers \& Structures Volume 87, Issues 13-14, July 2009, Pages 913-929, https://doi.org/10.1016/j.compstruc.2009.03.006

[5]. Selçuk Erkaya, Selim Doğan, Şaban Ulus, Effects of joint clearance on the dynamics of a partly compliant mechanism: Numerical and experimental studies, Mechanism and Machine Theory, Volume 88, June 2015, Pages 125-140, [https://doi.org/10.1016/j.mechmachtheory.2015.02.007

[6]. Wen Wang, Wenjun Qiu,He Yang, Haimei Wu, Guang Shi, Zhanfeng Chen, Keqing Lu, Kui Xiang, and Bingfeng Ju, An Improved Capacitive Sensor for Detecting the Micro-Clearance of Spherical Joints, Sensors (Basel). 2019 Jun; 19(12): 2694. Published online 2019 Jun 14. doi: $10.3390 / \mathrm{s} 19122694$

[7]. Zhang Jing, Guo Hong-Wei, Liu Rong-Qiang, Deng Zong-Quan, Nonlinear Characteristic of Spherical Joints with Clearance, J.Aerosp. Technol. Manag. vol.7 no.2 São José dos Campos Apr./June 2015 https://doi.org/10.5028/jatm.v7i2.464 